\title{
The effect of prehepatic insulin administration on alanine flux rates in diabetic dogs
}

\author{
E.-J. Freyse, U. Fischer, G. Albrecht, S. Marx and H. Keilacker \\ Central Institute of Diabetes "Gerhardt Katsch", Karlsburg, GDR
}

Summary. The in vivo flux rates of glucose $\left(6-{ }^{3} \mathrm{H}\right.$-glucose $)$ and of alanine $\left(\mathrm{U}-{ }^{14} \mathrm{C}\right.$-alanine) were measured in insulin-dependent chronically diabetic dogs which were infused with insulin employing a bedside-type artificial B cell and either the peripheral or the portal venous route. In comparison with non-diabetic control animals the diabetic dogs had near-normal patterns of glucose metabolism and pancreatic glucagon regardless of the route of insulin administration. They also showed reduced basal portal but moderately elevated peripheral insulin levels on peripheral and near-normal peripheral values on portal insulin infusion. Both concentration and production rates of alanine were reduced on peripheral $\left(0.142 \pm 0.016 \mathrm{mmol} / 1, \quad 4.73 \pm 0.49 \mu \mathrm{mol} \cdot \mathrm{kg}^{-1} \cdot \mathrm{min}^{-1}, \quad p<\right.$ $0.05)$ but normal on portal insulin $(0.206 \pm 0.030 \mathrm{mmol} / \mathrm{l}$, $\left.6.33 \pm 0.63 \mu \mathrm{mol} \cdot \mathrm{kg}^{-1} \cdot \mathrm{min}^{-1}\right)$. The alanine clearance was slightly elevated or normal in the diabetic dogs, and the glucose production from alanine showed a strongly delayed response to an exogenous glucose load on either route of insulin administration. It is concluded that the peripheral hyperinsulinism during posthepatic insulin administration stimulates glucose utilisation to a normal extent, but inhibits the provision of amino groups in resting muscle. Alanine synthesis is thereby reduced, and the carbon moieties are shunted from glucose into circulating lactate. Long-term studies are needed to elucidate the role of the liver under these conditions.

Key words: Alanine metabolism, insulin-dependent diabetes, dog, isotopic study, portal insulin infusion, artificial B cell.
It has been shown that the peritoneal route of insulin administration might improve the clinical results in Type 1 (insulin-dependent) diabetic patients who may otherwise be insufficiently managed [1, 2]. However, the requirement of prehepatic insulin administration for complete metabolic normalisation in insulin-dependent diabetes is still an unsettled topic. Both from clinical studies and from animal experiments it is well known that an automated insulin therapy on the posthepatic route will usually more or less restore the physiological blood glucose pattern; however, distinct abnormalities will remain as elevated circulating concentrations of glucose precursors [3-7] and diminished rates of glucose carbon circulation [3, 8]. Alanine is one key substrate which is produced in a glucose-dependent amount [9] and predominantly metabolised in the liver [10]. During short-term closed-loop insulin therapy in diabetic dogs, increased alanine flux rates were observed in combination with normal blood glucose control and peripheral hyperinsulinaemia [11].

Similarly, in long-term studies the circulating alanine concentrations were elevated in diabetic dogs re- ceiving their insulin on the posthepatic route either from pancreatic grafts or by means of portable pumps $[6,12]$. Therefore, it was the aim of this study to compare intra-individually the effect of feedback-controlled prehepatic and posthepatic insulin administration on the flux rates of alanine in chronically diabetic dogs. It was found that in the resting state the plasma levels and production rates of alanine are normal when insulin is infused via the portal route; they are, however, reduced on peripheral venous infusions which produce a moderate hyperinsulinaemia.

\section{Materials and methods}

\section{Animals}

Four diabetic Alsatian dogs (mean \pm SEM; weight $28.0 \pm 0.7 \mathrm{~kg}$, age $44 \pm 4$ months, duration of diabetes $23 \pm 5$ months, daily subcutaneous insulin dose $1.20 \pm 0.08 \mathrm{IU} / \mathrm{kg}$, leucocyte count on the experimental day $13.9 \pm 2.0 \cdot 10^{9} 1^{-1}$ ) and five non-diabetic control dogs of both sexes were studied $(25.0 \pm 2.0 \mathrm{~kg} ; 37 \pm 6$ months, $12.6 \pm 1.9$. $\left.10^{9} 1^{-1}\right)$. Three animals of each group underwent the experiments 


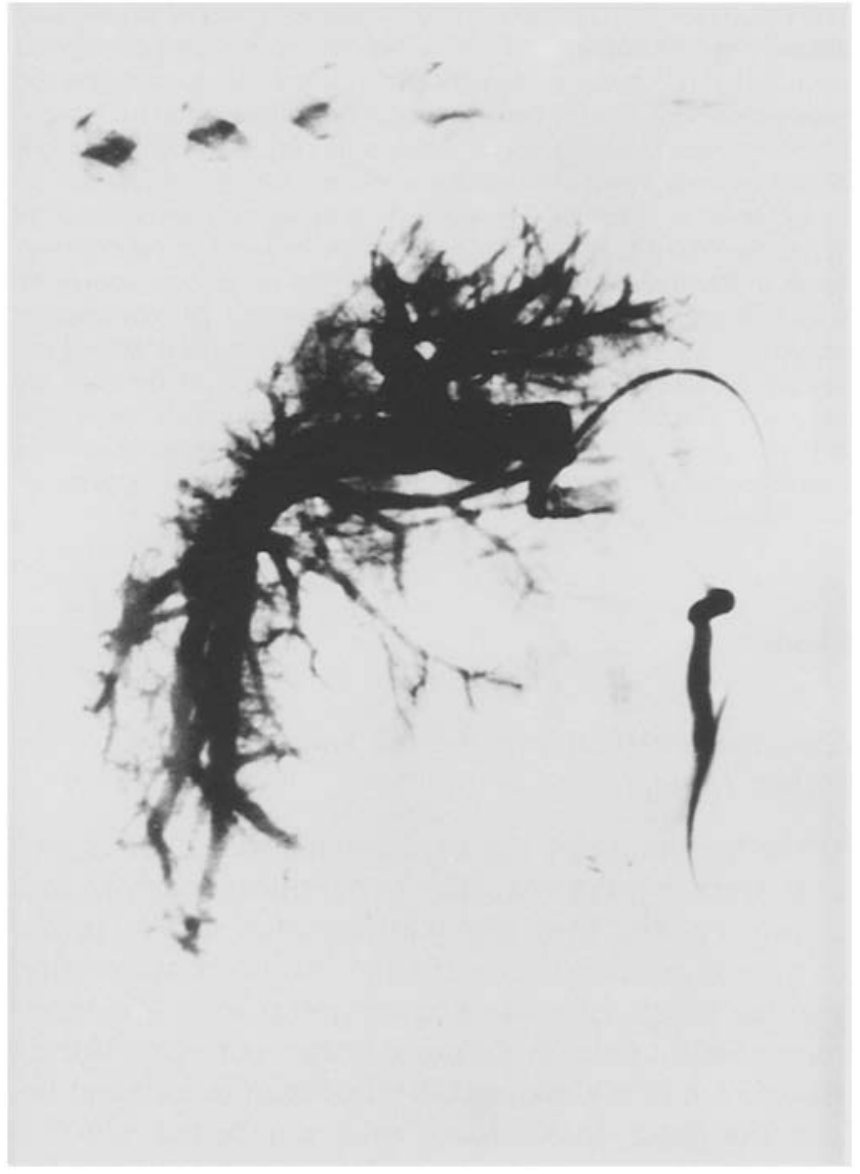

Fig. 1. Portography in a non-medicated nondiabetic dog. Catheter implantation 6 days before the X-ray study. Upper and left hand parts: portal vasculature of the liver, right side (below catheter which is positioned in the splenic vein): retrograde filling of mesenteric veins during infusion twice, resulting in a total number of 7 and 8 tests respectively. In a random order the diabetic dogs were submitted to peripheral and to portal venous insulin administration at intervals of between 1 and 2 weeks. Their body weight was constant over the entire study period. Production of diabetes by partial pancreatectomy and intra-arterial infusion of streptozotocin and animal handling have been previously described [13]. The animals were canine-C-peptide-negative and - under the routine subcutaneous treatment with regular porcine monocomponent insulin (Novo Industri, Copenhagen, Denmark) they did not develop anti-insulin antibodies over the years [14].

Portal venous catheters (silicone catheter $0.040 \times 0.085$ inches, Intracatheter Inc. Toronto, Canada) were implanted in all animals ap. proximately 6 weeks before the first experiment. They were introduced via the splenic vein up to the hepatic hilus. Their end was subcutaneously lead out into a harness pocket on the back. The catheters were flushed once a week with saline (no heparin applied). On the experimental day they were used for blood sampling or insulin infusion according to protocol. Before the first experiment the catheter position was verified by portography with $50 \mathrm{ml}$ Visotrast 370 (VEB Fahlberg-List, Magdeburg, GDR) employing the injector speed of between 10 and $20 \mathrm{ml} / \mathrm{s}$. During this procedure the dogs lay in a right side position and the $\mathrm{X}$-ray exposure was through the flank light path. The homogenous distribution of the contrast fluid from the catheter into hepatic vasculature documents that also a homogenous insulinisation of the liver may be expected during insulin infusion via this catheter (Fig. 1).

\section{Experimental protocol}

The animals were investigated after an overnight fasting period of $14 \mathrm{~h}$ (last insulin injection in the diabetic dogs at the time of the last meal) when they were quietly standing in a restraining harness (no medication). Additional catheters were acutely placed in the jugular vein for blood sampling and in the lower caval vein through saphenous vein for infusions. A plastic cannula was introduced into one cephalic vein for frequent plasma glucose determinations. These were needed to run the bedside-type artificial B cell to which the diabetic animals were connected from the beginning of the experiments [15]. They received the insulin either through the portal catheter (i.e. prehepatic) or through the lower caval catheter (i.e. posthepatic).

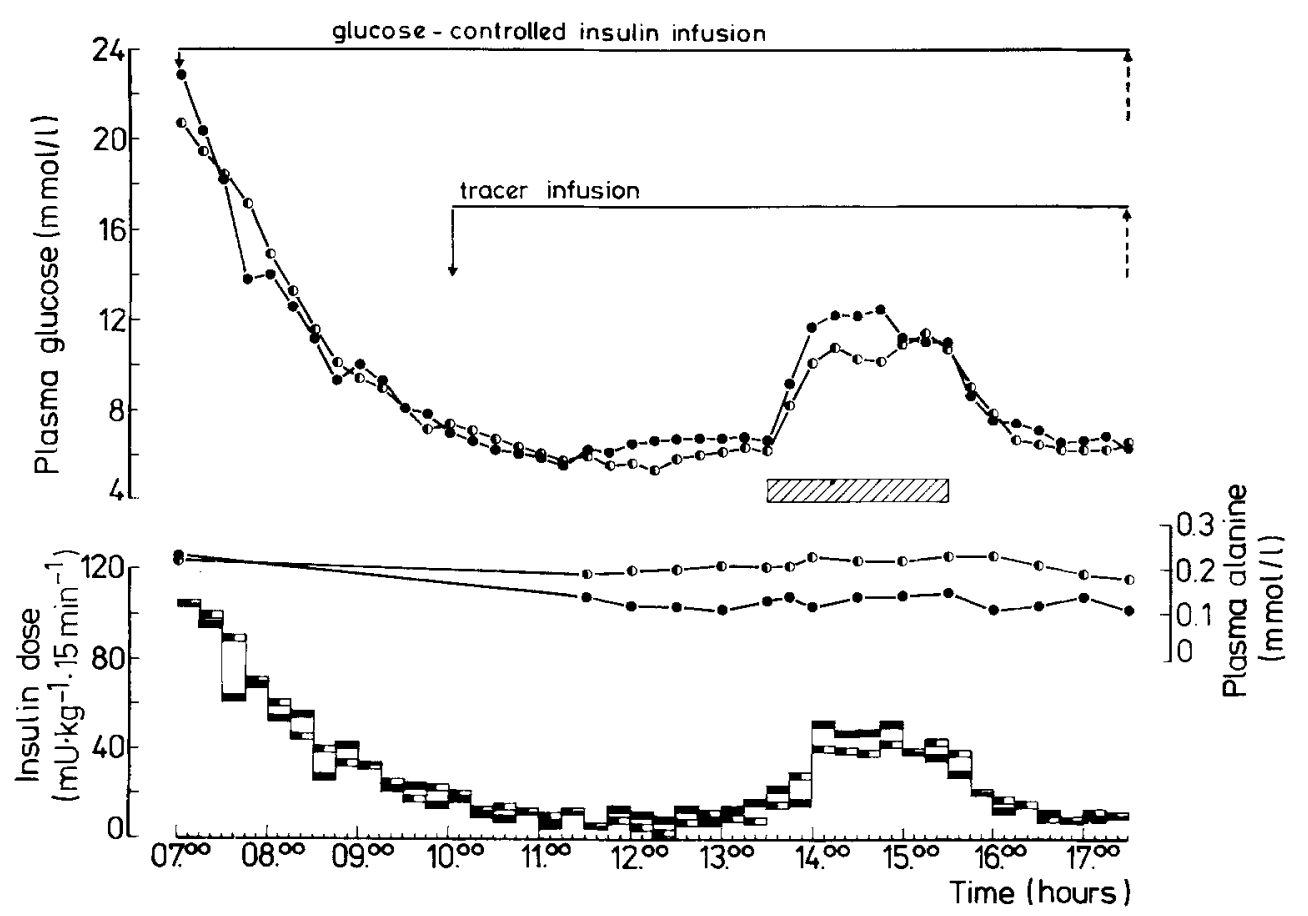

Fig. 2. Peripheral venous concentrations of plasma glucose (upper panel) and alanine (middle panel) and insulin doses summed up over 15 min (lower panel) in a diabetic dog during portal (half-filled symbols) or peripheral-venous (filled symbols) insulin infusions using a bedside-type artificial $B$ cell on two separate days three weeks apart. एב: intravenous infusion of $44.44 \mu \mathrm{mol} \cdot \mathrm{kg}^{-1} \cdot \mathrm{min}^{-1}$ unlabelled glucose. Peripheral venous blood for analyses of specific activities was sampled from 11.30 hours until the end of the experiments 
Identical algorithm parameters of insulin dosage $(\Delta t=5 \mathrm{~min})$ were used in all experiments.

One set of typical experiments in one diabetic dog is shown in Figure 2. The isotopic tracer infusion was commenced when glycaemia was close to normal, i.e. 3 to $4 \mathrm{~h}$ after the beginning of the glucose-controlled insulin infusion. At $210 \mathrm{~min}$ after the beginning of the tracer infusion, an additional intravenous load of unlabelled glucose was applied for $120 \mathrm{~min}$, and the animals were observed for another interval of $120 \mathrm{~min}$ after the end of this test. The control animals were studied in an identical manner, except they did not receive exogenous insulin. All experiments were timed to have the unlabelled glucose infusions at approximately the same clock hour, i.e. between 13.00 and 14.00 hours.

\section{Infusions}

L-U- ${ }^{14} \mathrm{C}$-alanine (8.0 MBq, sp. act. $4.400 \mathrm{GBq} / \mathrm{mmol}$ ) from the Institute of Radioisotopes Praha (Praha, CSSR) and D-6- ${ }^{3} \mathrm{H}$-glucose (37.0 MBq, sp. act. 1.147 TBq/mmol) from Amersham International (Amersham, Bucks, UK) were chromatographically purified the day before the experiment and then dissolved with $50 \mathrm{ml}$ saline $(0.154 \mathrm{~mol} / 1)$. Ten percent of the total dose $-0.8 \mathrm{MBq}{ }^{14} \mathrm{C}$-alanine and $3.7 \mathrm{MBq}^{3} \mathrm{H}$-glucose - were applied as a bolus injection to prime the constant infusion of approximately $16 \mathrm{KBq} / \mathrm{min}{ }^{14} \mathrm{C}$-alanine and $74 \mathrm{KBq} / \mathrm{min}{ }^{3} \mathrm{H}$-glucose, which was applied by a calibrated syringe pump (Perfusor $\mathrm{E}^{\circledR}{ }^{\circledR}$, B. Braun-Melsungen, Melsungen, FRG). Unlabelled glucose was individually dissolved with sterile water to give a dose of $44.44 \mu \mathrm{mol} \cdot \mathrm{kg}^{-1} \cdot \mathrm{min}^{-1}$ and to allow for an infusion rate of $1.0 \mathrm{ml} / \mathrm{min}$. Regular porcine monocomponent insulin (Novo Industri) was diluted with $10 \% \mathrm{v} / \mathrm{v}$ mixed homologous serum and with isotonic saline to give a concentration of $240 \mathrm{mU} / \mathrm{ml}$ for glucosecontrolled insulin infusions. All details, including the precise estimation of the applied tracer dose, have been extensively described $[8$, 11].

\section{Analyses}

During the experiments, serial measurements of peripheral venous plasma glucose concentration were performed at $5 \mathrm{~min}$ intervals employing the glucose oxidase $/ \mathrm{pO}_{2}$ technique (Beckman analyzer, Fullerton, Calif, USA). Blood sampling, separation and storage of plasma samples, insulin radioimmunoassay, deproteination, spectrophotometric analysis of glucose, lactate, alanine, $\beta$-hydroxybutyrate, and the preparation and determination of the specific radioactivities of ${ }^{3} \mathrm{H}$-glucose [8] and of ${ }^{14} \mathrm{C}$-alanine have been previously described [11].

For the determination of pancreatic immunoreactive glucagon $200 \mu$ l plasma containing 200 IU Trasylol (Bayer, Leverkusen, FRG) were incubated over $48 \mathrm{~h}$ at $4{ }^{\circ} \mathrm{C}$ with $50 \mu \mathrm{l}$ of $1: 20000$ diluted rabbit antiglucagon antiserum No. 185 of our own production. Fifty $\mu \mathrm{l}^{125} \mathrm{~J}$ glucagon $(50 \mathrm{pmol} / \mathrm{l})$ were added thereafter for a second incubation. One hundred $\mu 1$ 1:24 diluted goat antirabbit gamma globulin-antiserum were then added after preincubation for $1 \mathrm{~h}$ with $1: 400$ diluted normal rabbit serum. The antibody-bound ${ }^{125} \mathrm{~J}$-glucagon was precipitated after $30 \mathrm{~min}$ with $2 \mathrm{ml} 5 \%$ polyethylene glycol 4000 (Oxidwachs A, VEB Chemische Werke Buna, Schkopau, GDR) which was dissolved in 1:12 diluted normal human serum. All reagents including standard glucagon were made up with $0.05 \mathrm{~mol} / 1$ glycine buffer $\mathrm{pH} 8.6\left(0.1 \mathrm{~mol} / 1 \mathrm{NaCl}, 0.01 \% \mathrm{NaN}_{3}\right)$. The antiglucagon antiserum employed is directed against the C-terminal of the glucagon molecule, its cross reactivity with enteroglucagon was less than $0.3 \%$. The detection limit of the assay was $5.4 \mathrm{pmol} / 1$, at $30 \mathrm{pmol} / 1$ the inter- and intra-assay coefficients of variation were $9.1 \%$ and $2.9 \%$, respectively. Recovery of standard glucagon (Novo Industri) in 4 individual plasma samples was $98.7 \pm 5.5 \%$ (SEM).

\section{Statistical analysis}

The flux rates of glucose and of alanine were estimated on the basis of Steele's one-compartment model [16] as validated for non-steady state conditions [17]. The apparent distribution spaces of glucose and alanine were $200 \mathrm{ml} / \mathrm{kg}$ and $176 \mathrm{ml} / \mathrm{kg}$, respectively, as established previously [11]. Since the calculation of synthesis of glucose from the carbon moiety of alanine needs a model-based correction for isotope dilution within the tricarboxylic acid cycle [18], the percent glucose formation from alanine was calculated considering a correction by the factor 2.2 as validated by Hetenyi [19]. Since both the ${ }^{3} \mathrm{H}-$ and the ${ }^{14} \mathrm{C}$-glucose specific activities are diluted to the same extent by exogenous unlabelled glucose, the apparent rate of glucose formation from alanine ( $\%$ glucose- $\mathrm{C}$ from alanine $\times$ overall glucose appearance, $\left.\mu \mathrm{mol} \cdot \mathrm{kg}^{-1} \cdot \mathrm{min}^{-1}\right)$ could also be assessed for the period of unlabelled glucose administration. The means \pm SEM of the data are presented. The paired (intra-individual comparison portal vs peripheral insulin) or non-paired (comparison diabetic dogs vs control dogs) Student's t-test was applied to check the statistical significance of differences $(p \leq 0.05)$.

\section{Results}

\section{Glucose metabolism and plasma hormones (Tables 1 and 2)}

At the beginning of the experiments the diabetic animals were hyperglycaemic, hyperglucagonaemic and slightly ketotic; they also had elevated lactate levels. There was no measurable plasma insulin concentration in either the peripheral or in the portal vein. The metabolic abnormalities were more or less corrected during the 5 to $6 \mathrm{~h}$ of a glucose-controlled insulin infusion before the intravenous load with unlabelled glucose. During this interval, the animals remained slightly hyperglycaemic with normal glucose flux rates but insignificantly reduced metabolic clearance rates of glucose. This was true both for portal and peripheral insulin administration, i.e. for relative peripheral hypoinsulinaemia or hyperinsulinaemia respectively (Table 2). It also should be noted that neither the elevated $\beta$-hydroxybutyrate levels nor the lactate concentrations were fully restored to normal during the entire time of observation. The insulin doses required by the machine were nearly identical on both routes of administration: $\mathrm{mU} \cdot \mathrm{kg}^{-1} \cdot \mathrm{min}^{-1} 0.5 \pm 0.1$ portal vs $0.4 \pm 0.1$ peripheral. There was no appreciable difference among all these variables during the steady states before and after the exogenous glucose load.

The peripheral insulin levels were elevated but the portal levels were normal during intravenous infusion of unlabelled glucose in the diabetic dogs when they were on posthepatic insulin administration; their endogenous glucose production was suppressed to a normal extent, and their metabolic glucose clearance was normal as well. However, when they were on prehepatic insulin administration (tendency towards peripheral hypoinsulinaemia) their glucose tolerance was distinctly reduced on the basis of an impaired glucose clearance rate. The insulin doses applied during the glucose challenge were significantly higher during portal infusion:

$\mathrm{mU} \cdot \mathrm{kg}^{-1} \cdot(120 \mathrm{~min})^{-1} 298 \pm 9$ vs. $250 \pm 22(p<0.05)$. 
Table 1. Steady state data of glucose metabolism in normal and diabetic dogs on posthepatic or prehepatic insulin infusion

\begin{tabular}{|c|c|c|c|c|}
\hline & Interval & Control dogs & \multicolumn{2}{|l|}{ Diabetic dogs } \\
\hline $\begin{array}{l}\text { Plasma glucose } \\
(\mathrm{mmol} / 1)\end{array}$ & $\begin{array}{l}\text { Before experiment } \\
\text { Before GIT } \\
\text { During GIT } \\
1 \mathrm{~h} \text { after GIT } \\
2 \mathrm{~h} \text { after GIT }\end{array}$ & $\begin{array}{l}5.52 \pm 0.18 \\
5.34 \pm 0.19 \\
8.11 \pm 0.55 \\
4.49 \pm 0.16 \\
5.09 \pm 0.17\end{array}$ & $\begin{array}{r}20.35 \pm 1.11^{\mathrm{a}} \\
6.12 \pm 0.14^{\mathrm{a}} \\
9.83 \pm 0.42^{\mathrm{a}} \\
5.64 \pm 0.36^{\mathrm{a}} \\
5.46 \pm 0.23^{\mathrm{b}}\end{array}$ & $\begin{aligned} 21.99 & \pm 0.61^{\mathrm{a}} \\
6.27 & \pm 0.18^{\mathrm{a}} \\
10.82 & \pm 0.47^{\mathrm{a}} \\
6.51 \pm 0.33^{\mathrm{a}} & \pm .23^{\mathrm{a}}\end{aligned}$ \\
\hline $\begin{array}{l}\text { Metabolic clearance of glucose } \\
\left(\mathrm{ml} \cdot \mathrm{kg}^{-1} \cdot \mathrm{min}^{-1}\right)\end{array}$ & $\begin{array}{l}\text { Before GIT } \\
\text { During GIT } \\
1 \mathrm{~h} \text { after GIT } \\
2 \mathrm{~h} \text { after GIT }\end{array}$ & $\begin{array}{l}3.68 \pm 0.42 \\
5.94 \pm 0.33 \\
4.10 \pm 0.25 \\
3.80 \pm 0.34\end{array}$ & $\begin{array}{l}3.17 \pm 0.18 \\
5.21 \pm 0.23^{b} \\
4.09 \pm 0.31 \\
3.38 \pm 0.23\end{array}$ & $\begin{array}{l}3.02 \pm 0.34 \\
4.47 \pm 0.11^{\mathrm{a}} \\
4.16 \pm 0.25 \\
3.51 \pm 0.26\end{array}$ \\
\hline $\begin{array}{l}\text { Lactate } \\
(\mathrm{mmol} / \mathrm{l})\end{array}$ & $\begin{array}{l}\text { Before experiment } \\
\text { Before GIT } \\
\text { During GIT } \\
2 \text { h after GIT }\end{array}$ & $\begin{array}{l}0.590 \pm 0.070 \\
0.680 \pm 0.100 \\
0.620 \pm 0.090 \\
0.520 \pm 0.090\end{array}$ & $\begin{array}{l}1.490 \pm 0.215^{\mathrm{a}} \\
1.120 \pm 0.160^{\mathrm{a}} \\
1.270 \pm 0.280^{\mathrm{a}} \\
1.150 \pm 0.220^{\mathrm{a}}\end{array}$ & $\begin{array}{l}1.500 \pm 0.160^{\mathrm{a}} \\
0.890 \pm 0.110 \\
1.130 \pm 0.100^{\mathrm{a}} \\
0.960 \pm 0.110^{\mathrm{a}}\end{array}$ \\
\hline
\end{tabular}

Before experiment $=$ beginning of insulin administration, i.e. $180 \mathrm{~min}$ before isotopic tracer infusion. Before glucose infusion test $(\mathrm{GIT})=$ between 195 and 210 min after initiation of tracer infusion. During glucose infusion test $=$ between 315 and 330 min after initiation of tracer infusion, i.e. after 105-120 min of glucose infusion test. One and two hours after glucose infusion test $=$ between 375 and 390 min or 435 and $450 \mathrm{~min}$ after initiation of tracer infusion respectively. ${ }^{a} p<0.05$ for the differences between control dogs and diabetic dogs; ${ }^{b} p<0.05$ for the differences between portal and peripheral venous insulin administration; ${ }^{c} p<0.05$ for the differences between peripheral venous and portal insulin concentrations (cf. Table 2); ${ }^{d}$ i. e. after subtraction of the applied dose

Table 2. Circulating concentrations of pancreatic glucagon and of insulin in normal and in diabetic dogs on posthepatic or prehepatic feedback-controlled insulin infusion

\begin{tabular}{|c|c|c|c|c|}
\hline & Interval & Control dogs & \multicolumn{2}{|l|}{ Diabetic dogs } \\
\hline $\begin{array}{l}\text { Pancreatic glucagon } \\
\text { (nmol/1) }\end{array}$ & $\begin{array}{l}\text { Before experiment } \\
\text { Before GIT } \\
\text { During GIT } \\
1 \mathrm{~h} \text { after GIT } \\
2 \mathrm{~h} \text { after GIT }\end{array}$ & $\begin{array}{l}0.040 \pm 0.008 \\
0.045 \pm 0.009 \\
0.020 \pm 0.004 \\
0.030 \pm 0.006 \\
0.054 \pm 0.013\end{array}$ & $\begin{array}{l}0.145 \pm 0.048^{\mathrm{a}} \\
0.022 \pm 0.003^{\mathrm{a}} \\
0.014 \pm 0.003 \\
0.016 \pm 0.003^{\mathrm{a}} \\
0.020 \pm 0.003^{\mathrm{a}}\end{array}$ & $\begin{array}{l}0.149 \pm 0.047^{\mathrm{a}} \\
0.020 \pm 0.003^{\mathrm{a}} \\
0.014 \pm 0.001 \\
0.020 \pm 0.003 \\
0.023 \pm 0.003^{\mathrm{a}}\end{array}$ \\
\hline Portal vein & $\begin{array}{l}\text { Before experiment } \\
\text { Before GIT } \\
\text { During GIT } \\
1 \text { h after GIT } \\
2 \mathrm{~h} \text { after GIT }\end{array}$ & $\begin{array}{l}0.177 \pm 0.066^{\mathrm{e}} \\
0.162 \pm 0.010^{\mathrm{e}} \\
0.382 \pm 0.055^{\mathrm{e}} \\
0.129 \pm 0.020^{\mathrm{e}} \\
0.183 \pm 0.026^{\mathrm{e}}\end{array}$ & $\begin{array}{l}0.004 \pm 0.020^{\mathrm{a}, \mathrm{f}} \\
0.101 \pm 0.030^{\mathrm{f}} \\
0.346 \pm 0.066^{\mathrm{f}} \\
0.068 \pm 0.020^{\mathrm{f}} \\
0.096 \pm 0.030^{\mathrm{a}, \mathrm{f}}\end{array}$ & $\begin{array}{l}- \\
- \\
- \\
-\end{array}$ \\
\hline
\end{tabular}

For explanations cf. Table $1 .{ }^{\mathrm{e}} n=3,{ }^{\mathrm{f}} n=5$

\section{Alanine metabolism (Table 3)}

There was no difference in the initial circulating alanine concentration between the diabetic and the control dogs. Under posthepatic treatment with the artificial B cell the plasma alanine dropped significantly $(p \leq 0.05)$, but did not change on prehepatic insulin. The exogenous glucose administration did not further influence the plasma alanine levels. They remained low after the glucose load when the animals were on posthepatic insulin. Under these conditions the average rates of alanine appearance equaled those of dis- 
Table 3. Steady state data of alanine metabolism under the same conditions as in Tables 1 and 2

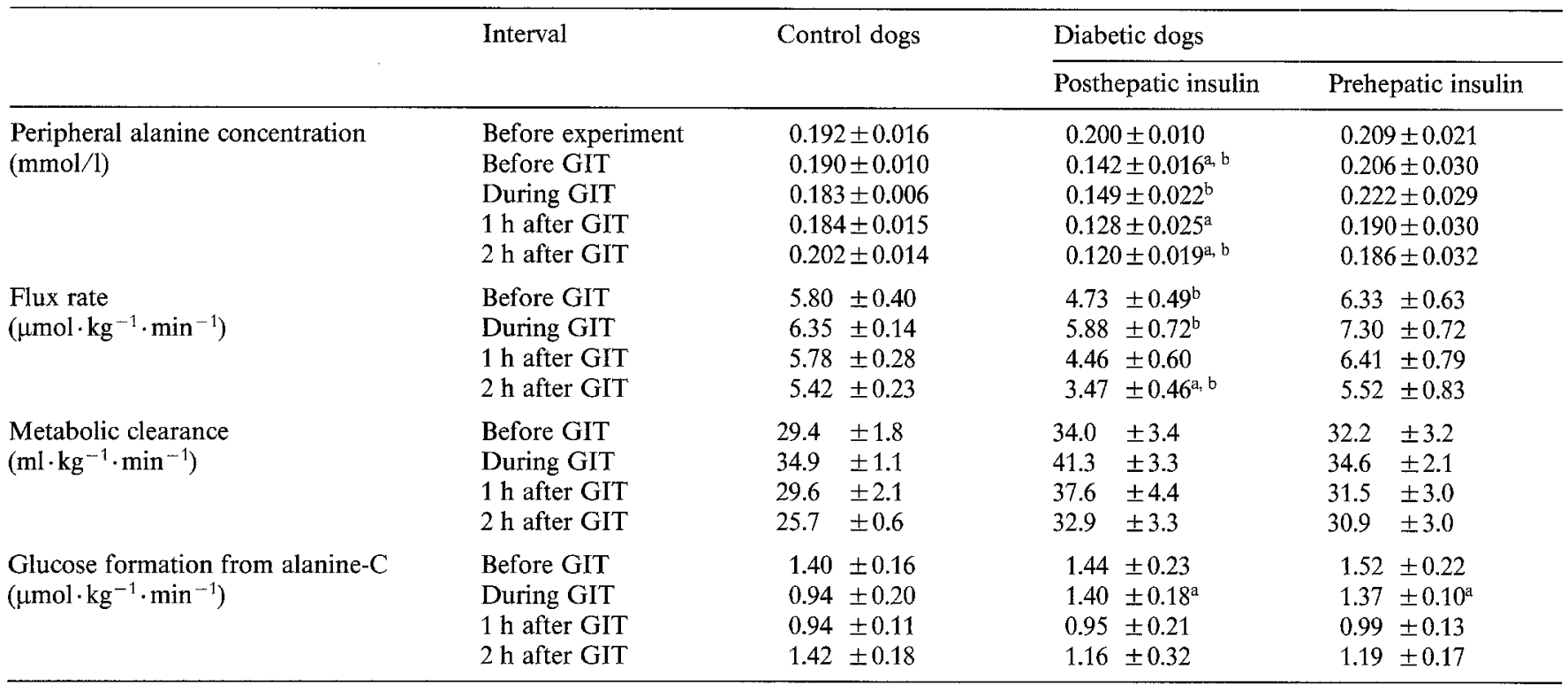

For explanations see Table 1

appearance. They were reduced when the diabetic animals were on posthepatic insulin administration but not when they were portally infused. There was in general a slightly continuous but transient increase in these rates during the glucose infusion test which was apparently higher in the diabetic dogs, with no appreciable difference between the two routes of insulin administration.

No difference appeared in the alanine clearance rates under basal conditions between the experimental groups. The transient but insignificant increase during the glucose infusion test, however, was slightly greater in the diabetic dogs during peripheral insulin administration.

Finally, under basal conditions the rates contributed by alanine to the carbon moiety of circulating glucose are approximately the same in all groups. However, the reduction due to the exogenous glucose load is delayed in the diabetic animals regardless of the route of insulin infusion.

\section{Discussion}

In the two experimental situations near-normal patterns of glucagon secretion and of blood glucose control including the glucose flux rates and its metabolic clearance were observed in diabetic dogs before and during the glucose load. There were, however, significant differences between the two routes of insulin administration in the overall metabolism of alanine, which is mainly produced in skeletal muscle as a result of glycolysis and of degradation of branched-chain amino acids $[20,21]$. Alanine utilisation is nearly exclusively guaranteed by the liver, where it serves as one of the main gluconeogenic substrates [10, 22]. It must, however, be taken into consideration that the overall metabolic rate of alanine is even higher due to a starvation-dependent enteric production [23]. Because of its hepatic utilisation, the gross flux rate is underestimated by the applied tracer technique [23, 24]. In this study, a relatively short-lasting and reproducible postabsorptive interval was chosen which gives rise to the assumption that mainly the extrasplanchnic site of alanine production is to be discussed. This study has shown reduced concentrations and flux rates of alanine when insulin was applied into the peripheral vein but not when portal infusions were given. From the lack of any difference between the groups before insulin infusion, it is concluded that the observed effects are in fact due to the experimental conditions. By posthepatic (i.e. peripheral venous) insulin administration a moderate peripheral hyperinsulinaemia and a lack of normal portal-peripheral insulin gradients or even an "under-insulinisation" of the liver has been produced. It may be speculated that under these conditions insulin-controlled metabolic processes in muscle which are connected to alanine production are altered on the basis of the chronically elevated insulin action which is more or less reversed by portal insulin administration. An elevated peripheral insulin action would stimulate the muscular uptake of glucose $[25,26]$, thereby feeding glycogen synthesis and glycolysis. Thus, lactate becomes the main product of glucose utilisation, even in resting muscle; this can be seen from the high circulating lactate levels. By these processes, a diminished oxidation of branched-chain amino acids is made possible $[27,28]$ which - in turn - reduces the availability of amino groups for alanine synthesis. This is in agreement with reported findings that an increase in peripheral insulin availability inhibits the production of alanine in skeletal muscle $[29,30]$. From these findings, 
however, no conclusion can be drawn on a "protein sparing" effect of high insulin levels in muscle; e.g. there is no relation between alanine output from skeletal muscle and the hepatic production of urea $[31,32]$. This may also explain why, in general, there is no direct connection between the rates of glucose uptake and of alanine output in skeletal muscle [33-36]. Accordingly, in a previous study in diabetic dogs with short-term peripheral insulin administration but a higher degree of peripheral hyperinsulinism and a higher exogenous glucose load, we have seen elevated alanine production rates [11]. Also, it is demonstrated by this study that, despite a near-normal control of overall hepatic glucose production, the utilisation of alanine appears unrestricted in relation to the prevailing plasma level. This leads to normal or - in the case of relative hepatic underinsulinisation during peripheral venous insulin infusion - to slightly elevated metabolic clearance rates of alanine and to a normal contribution of its carbon moiety to gluconeogenesis [23, 37, 38]. This may be explained on the basis of our observation of normal peripheral glucagon levels and therefore of an apparently diminished hepatic insulin: glucagon ratio. These findings are in agreement with several published investigations which have provided evidence that the utilisation of alanine increases over a broad range of physiological and pathophysiological plasma concentrations [33, 39]. It should, however, be mentioned that regardless of the route of insulin administration the response to exogenous glucose of the rate of glucose formation from alanine was distinctly delayed in these chronically diabetic animals. In addition, the slightly elevated levels of beta-hydroxybutyrate and lactate indicate that certain hepatic enzyme activities need more time for full restoration than that provided by the 5 or $6 \mathrm{~h}$ of a glucose-controlled insulin infusion.

Taken together, the abnormalities observed in alanine concentration and flux rates in insulin-dependent diabetic dogs on peripheral but not on portal venous insulin administration with a near-physiological control of glucose flux rates are obviously due to differences in peripheral insulin supply. These abnormalities may also, at least in part, explain the reduced rates in carbon re-circulation which we and others have also seen under similar conditions $[3,8]$. The slight remaining abnormalities in the control of hepatic alanine carbon flux into circulating glucose are obviously not due to differences in actual hepatic insulinisation. This may be elucidated by comparing the effects of short-term (as shown here) and of long-term improved insulin provision and optimal blood glucose control.

In conclusion, there is indeed no doubt that full normalisation of the entire metabolic network can only be reached by portal insulin administration $[9,11,12]$, but no convincing argument has emerged from this study to favour any prehepatic route per se in relation to posthepatic ones. However, different approaches may be taken into consideration to solve the problem of peripheral hyperinsulinism with respect to possible harmful effects on vasculature $[40,41]$.

Acknowledgements. This study was part of the Research Project HFR M 22 of the Ministry of Health of the German Democratic Republic. Angiographies were kindly performed by Dr. K.-O. Kagel, X-ray Department of the Clinic of Radiology of the Ernst-Moritz-ArndtUniversity, Greifswald. The skillful technical assistance of Ms. K. Brüllke, Ms. H. Schröder and Ms. H. Buff is gratefully acknowledged. The insulin radioimmunoassays were supervised by Dr. W. Besch.

\section{References}

1. Irsigler K, Kritz H, Hagmüller G, Franetzki H, Prestele K, Thurow $\mathrm{H}$, Geisen $\mathrm{K}$ (1981) Long-term continuous intraperitoneal insulin infusion with an implanted remote-controlled insulin infusion device. Diabetes 30: 1072-1075

2. Stephen RL, Maxwell IG, Kablitz C, Jacobsen SC, Hanover BK, Tryler FH (1983) Intraperitoneal insulin regimes and diabetic nephropathy. Proc Eur Dial Transplant Assoc 20: 692-697

3. Nosadini R, Noy GA, Nattrass M, Alberti KGMM, Johnston DG, Home PD, Ørskov H (1982) The metabolic and hormonal response to acute normoglycaemia in Type 1 (insulin-dependent) diabetes: studies with a glucose controlled insulin infusion system (artificial endocrine pancreas). Diabetologia 23: $220-228$

4. Albisser AM, Zinman B, Marliss EB, Botz CK (1980) The metabolic and hormonal responses to glucose infusion in anaesthetized normal and diabetic dogs controlled by an artificial B-cell. Diabetologia 18: 479-485

5. Nattrass M, Alberti KGMM, Buckle ALJ, Cluett B, Jaspan JB, Noy GA, Stubbs WA, Walton R (1979) Metabolic studies during normoglycaemic clampling of insulin dependent diabetics using a glucose-controlled insulin infusion system. Horm Metab Res [Suppl] 8: 86-92

6. Albisser AM, Goriya Y, Bahoric A, Marliss EB, Zinman B (1980) Persistent hormonal and metabolic abnormalities inspite of glucose normalization: long term studies with peripheral open-loop insulin delivery in diabetic dogs. In: Waldhäusl WK (ed) Diabetes 1979. Proceedings 10th IDF Meeting, Vienna 1979, Excerpta Medica, Amsterdam Oxford Princeton, pp 644-648

7. Hanna AK, Zinman B, Nakhooda AF, Minuk HL, Stokes EF, Albisser AM, Leibel BS, Marliss EB (1980) Insulin, glucagon, and amino acids during glycemic control by the artificial pancreatic in diabetic man. Metabolism 29: 321-332

8. Freyse EJ, Fischer U, Albrecht G (1983) Glucose metabolism studied isotopically in diabetic dogs: effect of restoration of peripheral normoinsulinaemia by the artificial $\mathrm{B}$ cell. Diabetologia 25: 411-417

9. Wolfe RR, Shaw IHF, Jahoor F, Herndon DN, Wolfe MH (1986) Response to glucose infusion in humans: role of changes in insulin concentration. Am J Physiol E 13: 306-311

10. Gelfand RA, Glickman MG, Jacob R, Sherwin RS, DeFronzo RA (1986) Removal of infused amino acids by splanchnic and leg tissue in humans. Am J Physiol E 13: 407-413

11. Freyse EJ, Fischer U, Albrecht G, Salzsieder E (1985) Alterations in alanine metabolism in diabetic dogs during short-term treatment with an artificial B cell. Diabetologia 28:763-768

12. Albisser AM, Nomura M, Greenberg GR, McPhedran NT (1986) Metabolic control in diabetic dogs treated with pancreatic autotransplants and insulin pumps. Diabetes 35:97-100

13. Freyse EJ, Hahn von Dorsche H, Fischer U (1982) Low dose streptozotocin diabetes after partial pancreatectomy in dogs. Histological findings in a new type of experimental diabetes. Acta Biol Med Germ 41: 1203-1210 
14. Fischer U, Besch W, Freyse EJ (1985) Canine C-peptide for characterization of experimental diabetes in dogs. Endocrinol Exp 19: $139-145$

15. Fischer U, Jutzi E, Bombor H, Freyse EJ, Salzsieder E, Albrecht G, Bruns W (1980) Assessment of an algorithm for the artificial $B$ cell using the normal insulin-glucose relationship in diabetic dogs and man. Diabetologia 18: 97-107

16. Steele R, Wall JS, de Bodo RC, Altszuler N (1956) Measurement of size and turnover rate of body glucose pool by the isotope dilution method. Am J Physiol 187: 15-24

17. Radziuk J, Norwich KH, Vranic M (1974) Measurement and validation of non-steady state turnover rates with application to the insulin and glucose systems. Fed Proc 33: 1855-1864

18. Kelleher JK (1986) Gluconeogenesis from labeled carbon: estimating isotope dilution. Am J Physiol E 13: 296-305

19. Hetenyi $G$ (1982) Correction for the metabolic exchange of ${ }^{14} \mathrm{C}$ for ${ }^{12} \mathrm{C}$ atoms in the pathway of gluconeogenesis in vivo. Fed Proc 41: 104-109

20. Ruderman NB, Berger M (1974) The formation of glutamine and alanine in skeletal muscle. J Biol Chem 249: 5500-5506

21. Haymond MW, Miles JW (1982) Branched chain amino acids as a major source of alanine nitrogen in man. Diabetes 31: $86-89$

22. Felig P, Wahren J (1971) Amino acid metabolism in exercising man. J Clin Invest 50: 2703-2714

23. Chiasson JL, Atkinson RL, Cherrington AD, Keller U, SinclairSmith BC, Lacy WW, Liljenquist JE (1979) Effects of fasting on gluconeogenesis from alanine in non-diabetic man. Diabetes 28: $56-60$

24. Chiasson JL, Liljenquist JE, Sinclair-Smith BC, Lacy WW (1975) Gluconeogenesis from alanine in normal postabsorptive man. Intrahepatic stimulatory effect of glucagon. Diabetes $24: 574-584$

25. Thiebaud D, Jacot E, De Fronzo RA, Maeder E, Jequier E, Felber JP (1982) The effect of graded doses of insulin on total glucose uptake, glucose oxidation and glucose storage in man. Diabetes 31: 957-963

26. Kruszynska YT, Home PD, Alberti KGMM (1986) In vivo regulation of liver and skeletal muscle glycogen synthase activity by glucose and insulin. Diabetes 35: 662-667

27. Odessey R, Khairallah EA, Goldberg AL (1974) Origin and possible significance of alanine production by skeletal muscle. J Biol Chem 249: 7623-7629

28. Chang TW, Goldberg AL (1978) The origin of alanine produced in skeletal muscle. J Biol Chem 253: 3677-3684

29. Mohan C, Bessman SP (1981) Insulin "inhibition" of gluconeogenesis by stimulation of protein synthesis. Biochem Med 26: $403-426$
30. Grubb B (1976) De novo synthesis of alanine by the perfused rat hindlimb. Am J Physiol 230: 1379-1384

31. Wolfe RR, Wolfe MH, Nadel ER, Shaw JHF (1984) Isotopic determination of amino acid-urea interactions in exercise in humans. J Appl Physiol 52: 458-466

32. Wolfe RR, Shaw JHF, Jahoor F, Herndon DN, Wolfe MH (1986) Response to glucose infusion in humans: role of changes in insulin concentration. Am J Physiol 250: E306-E311

33. Robert JJ, Bier DM, Zhao XH, Matthews DE, Young VR (1982) Glucose and insulin effects on de novo amino acid synthesis in young men: studies with stable isotope labeled alanine, glycine, leucine, and lysine. Metabolism 31: 1210-1218

34. Hetenyi G, Pagurek B, Dittmar EA, Ferrarotto C (1980) The effects of methylprednisolone and diabetes on the turnover of alanine and on the transfer of carbon atoms from alanine to pyruvate and glucose in dogs. Can J Physiol Pharmacol 58: 787-796

35. Yang RD, Matthews DE, Bier DM, Wen ZM, Young VR (1986) Responses of alanine metabolism in humans to manipulation of dietary protein and energy intakes. Am J Physiol E 13: 39-46

36. Hall SEH, Braaten JT, Mekendry JBR, Bolton T, Foster D, Berman $M$ (1979) Normal alanine-glucose relationships and their changes in diabetic patients before and after insulin treatment. Diabetes 28: 737-745

37. Sacca L, Trimarco B, Perez G, Rengo F (1977) Studies on the mechanism underlying the influence of alanine infusion on glucose dynamics in the dog. Diabetes 26: 262-270

38. Cherrington AD (1981) Gluconeogenesis: its regulation by insulin and glucagon. In: Brownlee M (ed) Diabetes mellitus, Vol 3. Sarlend SPIM Press, New York, pp 49-117

39. Felig $P$ (1973) The glucose-alanine cycle. Metabolism 22: 179-207

40. Stout RW (1971) The effect of insulin on the incorporation of sodium $\left(1-{ }^{14} \mathrm{C}\right)$-Acetate into the lipids of the rat aorta. Diabetologia 7: $367-372$

41. Stout RW, Bierman EL, Ross R (1975) Effect of insulin on the proliferation of cultured primate arterial smooth muscle cells. Circ Res 36 : 319-327

Received: 10 November 1986

and in revised form: 21 April 1987

Dr. E.-J. Freyse

Central Institute of Diabetes

"Gerhardt Katsch"

DDR-2201 Karlsburg

German Democratic Republic 